\title{
Promoting Thinking Skills within the Secondary Classroom Using Digital Media
}

\author{
Maree A. Skillen \\ Arden Anglican School 50 Oxford Street, Epping, Australia \\ m.skillen@arden.nsw.edu.au
}

\begin{abstract}
One of the recurring themes concerning the integration of ICT into secondary education relates to opportunities for moving classroom-based activities for learners towards higher levels of thinking and learning. The research described in this paper involved an investigation of the implementation of digital media into a New South Wales Year 9/10 IST (Information and Software Technology) elective course. It concentrated on the subsequent assessment and impact that the software has had on creating an inquiry-based situation to promote higher-order thinking skills of students within a secondary classroom completing digital media projects for the web. The case study of a composite class of fifteen Year 9 and 10 students utilised a mixed methodology involving both qualitative and quantitative procedures. Results from the study suggested that technology allowed learning and motivation of students to be enhanced and that there was a willingness exhibited by individuals to engage in tasks and discussions. It is argued that teaching and learning can be enriched as the technological tools and pedagogical processes are brought together in appropriate ways. By referring to the integration of technology as being a meaningful tool that will transform the culture of schools but requires attention to the habits of mind; newly defined thinking tasks such as problem solving, and the necessary cognitive operations such as analysing, inferring and evaluating are possible.
\end{abstract}

\section{Introduction}

This study emerged from an interest and experience of multimedia in the secondary classroom. The research described focused particularly on an interest in how technology is used as a tool in the teaching and learning process with particular emphasis on the concept of constructivism and the emphasis that a constructivist perspective has on students' evolving knowledge, the critical role social negotiation 
plays in helping students interpret their experiences and the promotion of thinking skills when using technology. Further, it is identified that the primary responsibility of the instructional expert is to create and maintain a collaborative problem-solving environment. Hackbarth [7] supports this view by referring to constructivism as having become a dominant force in education. The essential principle of this revolutionary theory is that each of us assembles the bits and pieces of our experience in ways that, in many respects, are unique. Drawing upon prior conceptions and feelings, we actively interact with our surroundings in an ongoing effort to make the diversity of our experiences all sensible and coherent. The essential challenge of constructivism has been in its shifting the locus of control over learning from the teacher to the student. Educational technologists, with their roots in behavioural psychology, have long sought to design programs in such a way that students would be enticed to achieve pre-specified objectives. Constructivists have claimed that this violates both what we now know about the nature of learning (situated, interactive) and about the nature of knowledge (perspectival, conventional, tentative, evolutionary). They have maintained that objectives should be negotiated with students based on their felt needs, that planned activities should emerge from within the contexts of their lived worlds; that students should collaborate with peers in the social construction of personally significant meaning, and that evaluation should be a personalised, ongoing, shared analysis of progress.

The influences of constructivism on educational technology can be seen in many areas. Models of communication can portray the process as interactive, with the message as much determined by the selective perception of the recipient as by the style of the author. Mediated programs are seen now more in terms of providing students with opportunities to expand their horizons. Interactive multimedia presentations are seen to provide students with insights into the thinking of experts, and the "scaffolding" needed to enable their own uniquely coloured construction of disciplined knowledge. Romiszowski [14] defines interactive instruction as a process in which the learner is involved in overtly responding to material by making selections or giving answers to questions. He continues by commenting that interactivity in the instructional process operates by setting tasks for the learner to deal with but its value and its nature are best described by the "depth of processing" or the quality of thinking that is demanded from the student. Interactive multimedia (IMM) comes in various forms and has the potential to enhance education though there has been little opportunity for educators to gain experience in how to effectively use and critically evaluate this new media [15]. IMM products have the capacity to shift the locus of 'ownership' and 'control' in learning. Whereas learning has traditionally been 'controlled' by the teacher, the instructor or the computerbased instructional system, the end-users of IMM courseware can be empowered to own and control their own learning [9]. IMM is a particularly effective medium for providing such search-through-problem environments. The other central issue in IMM instructional design is the design philosophy of increasing learner control over the 'what' and the 'how' of learning. It is important for designers of IMM products to provide the end-user with 'a handful of simple ways to travel from one object to another (by keyword, object search, text type or random choice) which lets people create many paths through a rich territory without getting lost or hitting a dead-end'. 


\section{Aims of the Study}

The goals of the study involved the amalgamation of two aims, namely, an investigation into the evaluation and implementation of digital media which includes multimedia and web-based solutions, and an examination of their effect on and contribution to the learning environment in relation to the promotion of thinking skills among students. These may be expressed in terms of the following objectives: (1) To evaluate the educational value of a variety of digital media; (2) To investigate the contribution of digital media in the development of an inquiry-oriented learning environment; (3) To enhance students' skills in the use of digital media; and (4) To develop, implement and evaluate the use of inquiry-based learning with digital media through a social constructivist environment.

\subsection{Research Questions}

In order to provide a focus for these objectives, the following research questions were formulated: (1) Can digital media contribute to and enhance inquiry-based learning within the secondary classroom? (2) What is the impact of using digital media on students' abilities in the classroom learning environment? (3) How does digital media enable the student to develop higher-order thinking skills? (4) How can constructivist strategies be promoted through the development and use of digital media?

\section{Significance}

It was anticipated that this research would contribute to future investigations related to the teaching and learning of secondary students within technology-orientated classrooms. In particular, the research study is significant for a number of reasons. Firstly, it is likely to provide new information about the extent to which students can develop higher-level thinking skills using web authoring tools that utilise digital media. Secondly, it is likely to provide information related to the contribution that these tools have on changing the learning environment to be inquiry-oriented. This would support the research conducted by Coulter [5] who investigated the role that technology has played in the provision for and enhancement of an inquiry environment. The third area to which the study is likely to contribute is in facilitating comparisons with the work of Cooper and Maor [4] who utilised multimedia to create a student-centred learning environment. Cooper and Maor [4] based some of their research investigations on the work of Grabinger [6] who posed questions including: How can we design machines to help people learn and think? Can we use machines to help make the learning processes visible and more accessible? Further comparative information can be gathered and considered from the studies conducted by Maor and Taylor [11] who examined student achievements related to higher-level thinking skills, and the investigation of the mediation role of teachers' epistemologies in high school computerised classes. In addition, studies by Maor and Fraser [10] concentrating on how the use of a classroom environment instrument can 
monitor perceptions in evaluating inquiry-based CAL are relevant. These investigations may provide comparative results related to the analysis of a technology content-based classroom, its environment and the actual and preferred perceptions of the students and teachers. The study is likely to contribute to investigations related to constructivism and the work of Jonassen [8] supports this. In particular, he has examined constructivist perspectives for learning with technology, computers as mindtools for engaging learners as critical thinkers, and using computers as cognitive tools. The findings from this study will refer to the literature and highlight particular findings of significance that support and add to the identified areas of investigation.

\section{Research Methodology}

\subsection{Sample}

Fifteen students, aged 14 to 16 years, and one secondary Computing Studies classroom teacher participated in this case study. Participating students were enrolled in a Year 9/10 IST elective course: Internet and Web Design. The area of Computing Studies was selected for the study because of the requirements from the New South Wales Board of Studies that students be familiar with the use of database design, digital media, Internet and website development and multimedia programs. The teacher involved in the study had 8 years teaching experience and limited involvement with the promotion of higher-level cognitive and inquiry-based learning.

\subsection{Instrumentation}

The instrumentation for this case study consisted of curriculum materials that involved the use of digital media with particular emphasis on the utilisation of Macromedia multimedia and web-based solutions for school project work - into a Year 9/10 IST elective course: Internet and Web Design. In the Information and Software Technology Years 7-10 syllabus documentation [13] states that, "People can expect to work and live in environments requiring highly developed levels of computing and technological literacy. Current technologies are becoming obsolete at a rapid rate and new generations will need to be flexible to accommodate changes as they emerge. It is important that students learn about, choose and use appropriate information and software technology and develop an informed awareness of its capacities, scope, limitations and implications. Technological competence in the rapidly evolving area of information and software technology will require lifelong learning". The general purpose of the school-based IST elective course at the NSW secondary school used for this case study was to focus students on designing and building their own websites to solve a given problem. For the duration of the school semester when visits and observations were made, students were required to analyse 
problems, plan solutions, research possibilities, develop webpages for their solution, design suitable graphics, test and finally evaluate the finished project. Students worked towards gaining a valuable real world experience using industry standard software such as Dreamweaver, Fireworks and Flash. Specifically, the IST course assisted students to develop the knowledge, understanding and skills to solve problems in real life contexts. Through experiential and collaborative tasks, students engaged in processes of analysing, designing, producing, testing, documenting, implementing and evaluating information and software technology-based solutions. Creative, critical and meta-cognitive thinking skills were developed through students' practical involvement in projects.

\subsection{Data Collection}

A 20-week classroom-based study was conducted to investigate whether the use of digital media programs can facilitate thinking and learning. The projected time for the study was equivalent to two NSW school terms. Both a qualitative and quantitative study was initiated through the implementation of this research. Specifically, the data collection methods implemented for this study included: a prequestionnaire; field notes (descriptive; observations); informal student and teacher discussions; formal student and teacher interviews; student work samples; computerbased student answer files; and a post-questionnaire. Staff and students responded to a classroom environment inventory prior to using the digital media and again 3 months after use was completed.

\subsection{Method}

The primary data gathering tool for this study was the 'What is Happening in this Class (WIHIC)' classroom environment instrument [1]. The WIHIC was used to examine how the teacher and students perceived the classroom environment to be with relation to the use of technology. It was used to gather data on both the preferred and actual perceptions of the staff and students involved. The WIHIC instrument was administered to both the teacher and students with a 3 month interval between the examination of each group's preferred and actual perceptions. A computer background survey was implemented with the class to obtain information from the fifteen students about their access to computer technology, use of computers both at home and at school, interest and personal assessment of the ease with which they use technology and regularity of use of the Internet and multimedia programs. The researcher assumed the role of a participant-observer [11] in the classroom of one teacher. This role enabled the researcher to monitor selected students application to task and thinking. Field notes were recorded by the researcher to document observations of both the teacher and students during each lesson. These notes recorded the learning processes taking place, whole-class discussions, individual interactions, student-student interactions and teacher-student interactions. Classroom observations and field notes were further supported by access to online entries made at the end of each lesson by students, during the second half of the school semester, in a diary of classwork to record responses to the following 
questions: (1) What have you completed in this lesson?, (2) What did you learn?, (3) What did you have trouble with? How did you solve it? An ethnographic or sociocultural interpretation [12] of student experiences was made through informal interviews and observations of selected students. The understanding of concepts and individual perceptions was reviewed and queried, together with an analysis of thinking skills, processes and reasons for completing a task in a given way. Emphasis was placed on the teacher providing students with frequent opportunities to work individually using computers, to work collaboratively with fellow students, and to participate in whole-class discussions. Informal discussions between the researcher and teacher occurred at the end of each class session during the investigation to focus on issues that may have arisen from the lesson and about teaching plans for the next class or subsequent follow-up sessions. A formal interview was conducted both at the commencement of the 20 week observation period and at the end.

\section{Results}

In response to the research questions posed for this study, early results suggested that technology allowed learning and motivation of students to be enhanced and that there was a willingness exhibited by individual students to engage in tasks and discussions. As they engaged in practical work during the IST elective course classes, students exhibited a number of characteristics central to this study including inquiry-based learning, improvements in skills (planning, technical, thinking, interacting with others) and a constructivist approach to project development. From the field study observations, it is felt that the implementation of digital media can contribute to and enhance inquiry-based learning. This was evident within the secondary technology classroom observed during the study, as a shift from the traditional teacher-centred instructional paradigm to a more student-centred one occurred. In working independently students in this study demonstrated during the semester that they had gained valuable skills (practical, technical, organisational, interrelationship, thinking) that were transferable to other academic endeavours. In creating a more student-centred approach through the use of technology integration it was observed that the use of digital media involving the Macromedia suite in the classroom, could encourage students to take charge of their own learning. When utilising Macromedia multimedia and web-based solutions for learning, students made a firm transition from simply receiving knowledge to becoming producers (constructivism) of their own school project work within a contextual element. This was further evidenced by student entries in a diary of classwork completed during the later part of the semester when students were working on their major project work for the IST elective course. The design of the digital media and web-based solution enabled students during their program of learning to demonstrate acquisition of knowledge, skills, ideas and understanding. In categorising the thinking skills employed by students during the development of the project work in the IST course being studied, reference to an established thinking skills framework is worthwhile for consideration [2]. Technology can be used as a tool for communication (visual, physical) and inquiry through the implementation of a constructivist approach that 
aims to foster student learning through real-life applications. Students in the study provided evidence that they had gained knowledge through self-exploration and active learning whilst remaining on task during lessons. Students remained entirely on task because their technology classwork centred on themes and concepts and the connections between them, rather than on isolated facts and information that they had difficulty understanding or making links to. The most obvious benefit of the Year 9/10 IST elective course was that students learnt about the web. They learnt about technologies related to the web, software used to create or control the web, and how to organise and present websites. In addition, students learnt to consider and plan their projects and to interact with others to strengthen or to reinforce a skill learnt.

\section{Conclusion}

Implications from this study for teaching and learning via a digital media approach include encouraging students to verbalise or to write down their thinking process and to identify patterns in their thoughts and possible gaps in their understanding whilst using technology constructively to allow for greater flexibility by students in terms of their cognitive processes. We need to be able to initiate and encourage learners within our classrooms to demonstrate and use effective thinking practices and for both students and teachers we need to consider ways of modelling, coaching and scaffolding thinking processes - this will allow learners to refine their understanding through articulation and comparison of strategies through the concept of reflection. The use of technology to allow students to reflect and evaluate on their project work and to therefore refine, organise and re-organise processes during the process of knowledge construction is also a key area for consideration.

We live in an information rich society that has been greatly enhanced by the advancement of digital media. As educators we need to consider and draw on the revolution of change and the manner in which information is presented in order to allow our students (learners) to be educated through means which are more relevant to society today. Digital media offers a motivating and imaginative approach to subject matter whereby students can be actively engaged and develop a variety of skills including problem solving, thinking, technical and interactivity. A central part to the learning process and the development of an individuals thinking is the concept of constructivism. The learning process is only effective when meaning is constructed by the student. In creating the product (project), students then own the information that they process more than if they were to simply find or be given it. Brearley [3] aptly captures the essence of what a constructivist approach is by stating that it is by no means a replacement for traditional content areas and strategies but rather "The main work of the school is surely the fostering and developing of mental life, enabling children to experience more fully and consciously all that life has to offer. This large, overall aim is to be achieved by an infinity of small steps. The material we provide children can seldom be thought of as an end in itself but rather as a means through which effective thinking and feeling are fostered". 


\section{References}

1. J. Aldridge, B. Fraser and T. Huang, Investigating classroom environments in Taiwan and Australia with multiple research methods. Journal of Educational Research, 93, 48-57 (1999).

2. L. Anderson and D. Krathwohl, A taxonomy for learning, teaching and assessing: a revision of Bloom's taxonomy of educational objectives, (Longman, New York, 2001).

3. M. Brearley, The Teaching of Young Children. (Schocken books, New York, 1969)

4. M. Cooper and D. Maor, (1998). Mathematics, multimedia and higher level thinking skills. Proceedings Western Australian Institute of Educational Research Forum 1998. http://education.curtin.edu.au/waier/forums/1998/cooper.html

5. B. Coulter, Technology for learning: how does technology support inquiry? Connect (a publication of Synergy Learning), 13(4), (March/April 2000).

6. R.S. Grabinger, in: Handbook of research for educational communications and technology, edited by D. H. Jonassen (Simon and Schuster Macmillan, new York, 1996), pp. 665-692.

7. S. Hackbarth, The Educational Technology Handbook - A Comprehensive Guide: Process and Products for Learning. (Englewood Cliffs, New Jersey, 1996)

8. D.H. Jonassen, Computers in the classroom: mind tools for critical thinking. (Prentice-Hall, Englewoods, NJ, 1996).

9. C. Latchem, J. Williamson and L. Henderson-Lancett (eds.), Interactive Multimedia: Practice and Promise. (Kogan Page, London, 1993).

10. D. Maor and B.J. Fraser, Use of classroom environment perceptions in evaluating inquiry-based computer-assisted learning. International Journal of Science Education. 18, 401-421, (1996).

11. D. Maor and P.C. Taylor, Teacher epistemology and scientific inquiry in computerised classroom environments. Journal of Research in Science Teaching. 32, 839-854 (1995).

12. S.B. Merriam, Qualitative research and case study: Application in education (2nd ed.), (Jossey Bass, San Francisco, 1998).

13. New South Wales Board of Studies, Information and Software Technology Years 7-10 syllabus documentation June 2003. (NSW Board of Studies, Sydney, 2003).

14. A.J. Romiszowski, Developing interactive multimedia courseware and networks. Paper presented at the meeting of the International Interactive Multimedia Symposium, (Western Australia, Perth, 1992)

15. K. Wiburg, Becoming critical users of multimedia. The Computing Teacher, 22, 59-61 (1995). 